\title{
DNA damage-induced activation of ATM promotes $\beta$-TRCP- mediated Mdm2 ubiquitination and destruction
}

\author{
Zhiwei Wang1,3, Hiroyuki Inuzuka', ${ }^{1,3}$ Jiateng Zhong 1,2, Hidefumi Fukushima', \\ Lixin Wan ${ }^{1}$, Pengda Liu' ${ }^{1}$ and Wenyi Wei ${ }^{1}$ \\ ${ }^{1}$ Department of Pathology, Beth Israel Deaconess Medical Center, Harvard Medical School, Boston, MA \\ ${ }^{2}$ Department of Pathophysiology, Norman Bethune College of Medicine, Jilin University, Changchun, P. R. China \\ ${ }^{3}$ Denotes equal contribution \\ Correspondence to: Wenyi Wei, email: wwei2@bidmc.harvard.edu

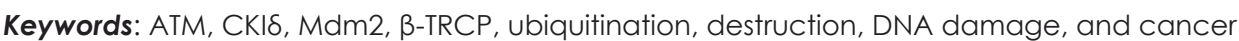 \\ Received: August 27, 2012, Accepted: September 09, 2012, Published: September 11, 2012
}

Copyright: ( ) Wang et al. This is an open-access article distributed under the terms of the Creative Commons Attribution License, which permits unrestricted use, distribution, and reproduction in any medium, provided the original author and source are credited.

\section{ABSTRACT:}

The Mdm2 oncoprotein promotes p53 ubiquitination and destruction. Yet, exact molecular mechanisms of Mdm2 destruction itself, under DNA damaging conditions, remain unclear. Recently, we identified SCF-TRCP as a novel E3 ligase that targets Mdm2 for ubiquitination and destruction in a Casein Kinase Iठ (CKIठ)-dependent manner. However, it remains elusive how the $\beta-\mathrm{TRCP} / \mathrm{CKI} / \mathrm{Mdm} 2$ signaling axis is regulated by DNA damage signals to govern p53 activity. Consistent with previous studies, we found that inactivation of the Ataxia Telangiectasia Mutated (ATM) kinase, in turn, impaired DNA damage-induced Mdm2 destruction. Although phosphorylation of Mdm2 at Ser395 (an ATM phosphorylation site) facilitated Mdm2 interaction with $\beta$-TRCP, Ser395A-Mdm2 was degraded non-distinguishably from WT-Mdm2 by SCF ${ }^{\beta}$-TRCP upon DNA damaging treatments. This indicates that in addition to phosphorylating Mdm2 at Ser395, ATM may govern Mdm2 stability through other unknown mechanisms. We further demonstrated that DNA damage-induced activation of ATM directly phosphorylated CKIठ at two well-conserved S/TQ sites, which promotes CKIठ nuclear localization to increase CKIס-mediated phosphorylation of Mdm2, thereby facilitating subsequent $\mathrm{Mdm} 2$ ubiquitination by $\mathrm{SCF}^{\beta-T R C P}$. Our studies provide a molecular mechanism of how ATM could govern DNA damage-induced destruction of Mdm2 in part by phosphorylating both Mdm2 and CKIס to modulate SCF-TRCP-mediated Mdm2 ubiquitination. Given the pivotal role of $\mathrm{Mdm} 2$ in the negative regulation of $\mathrm{p53}$, this work will also provide a rationale for developing CKIठ or ATM agonists as anti-cancer agents.

\section{INTRODUCTION}

Human cancer development has been characterized to be a multi-step process that is associated with both activation of multiple oncogenes and inactivation of various tumor suppressor genes [1]. The p53 gene is considered as one of the prototypical tumor suppressor gene, as abnormalities of the $\mathrm{p} 53$ gene have been observed in more than half of all human cancers [2]. The p53 tumor suppressor protein plays a critical role in anti-proliferation activity through inducing cell cycle arrest, senescence, and programmed cell death [3]. Additionally, p53 has been reported to have a physiological function in regulating cellular responses to DNA damage in part by inducing either G1 or G2 checkpoints, allowing sufficient time for cells to repair their damaged DNA [4]. Recent studies have also shown that p53 is involved in governing the cellular apoptotic pathway under conditions when cells are exposed to excessive DNA damage beyond the ability of cells to efficiently repair them [4]. Given the pivotal roles of p53 in various cellular processes, p53 activity is tightly regulated at multiple levels including transcription, translation and protein stability [5]. Although several E3 ubiquitin ligases including Mdm2 [6], E6AP [7], 
TOPORS [8] , RFFL [9], Cop1 [10] and Pirh2 [11] have been implicated in regulating p53 stability, mouse genetic studies strongly indicate that $\mathrm{Mdm} 2$ (mouse double minute 2) $[12,13]$ is the major negative regulator for $\mathrm{p} 53$ stability [6]. Consistent with the critical role of Mdm2 as the major physiological E3 ligase in promoting p53 destruction, the Mdm2 oncoprotein is frequently found to be overexpressed in a wide variety of human cancers [14]. Furthermore, mutations in the Mdm2 oncoprotein that disrupt ribosomal protein (RP)-mediated suppression of Mdm2 E3 ligase activity have been observed in human cancers [15]. In line with the critical role for Mdm2mediated degradation of p53 in favoring tumorigenesis, a specific Mdm2 inhibitor (MI-219) has been reported to synergize with oxaliplatin, which inhibits DNA synthesis, to exhibit superior anti-cancer effects in solid tumors types bearing wild-type p53 [16].

However, the exact molecular mechanisms underlying Mdm2 overexpression in human cancers remain largely elusive. We recently identified that both cell cycle regulated and DNA damage-induced turnover of Mdm2 is controlled by SCF ${ }^{\beta-T R C P}$-mediated ubiquitination of Mdm2 [17, 18]. We further defined a critical role for Casein Kinase I $\delta(\mathrm{CKI} \delta)$ in $\mathrm{SCF}^{\beta-\mathrm{TRCP}_{-}}$ mediated degradation of $\mathrm{Mdm} 2$ [17, 18]. Importantly, depletion of $\beta$-TRCP resulted in attenuated p53 activity, reduced pulsatile waves of $\mathrm{p} 53$ in response to persistent DNA damage, and increased resistance to DNA damageinduced apoptosis [18]. However, it remains largely uncharacterized how DNA damaging signals control $\beta$-TRCP-mediated Mdm2 destruction. Furthermore, even though CKI $\delta$ kinase was identified to play a critical role in mediating cell cycle-dependent destruction of Mdm2 by $\operatorname{SCF}^{\beta-T R C P}[17,18]$, it is not fully understood whether under the DNA damage conditions, the CKI $\delta$ kinase is activated to govern the Mdm2/p53 pathway.

To this end, multiple studies have demonstrated that

A

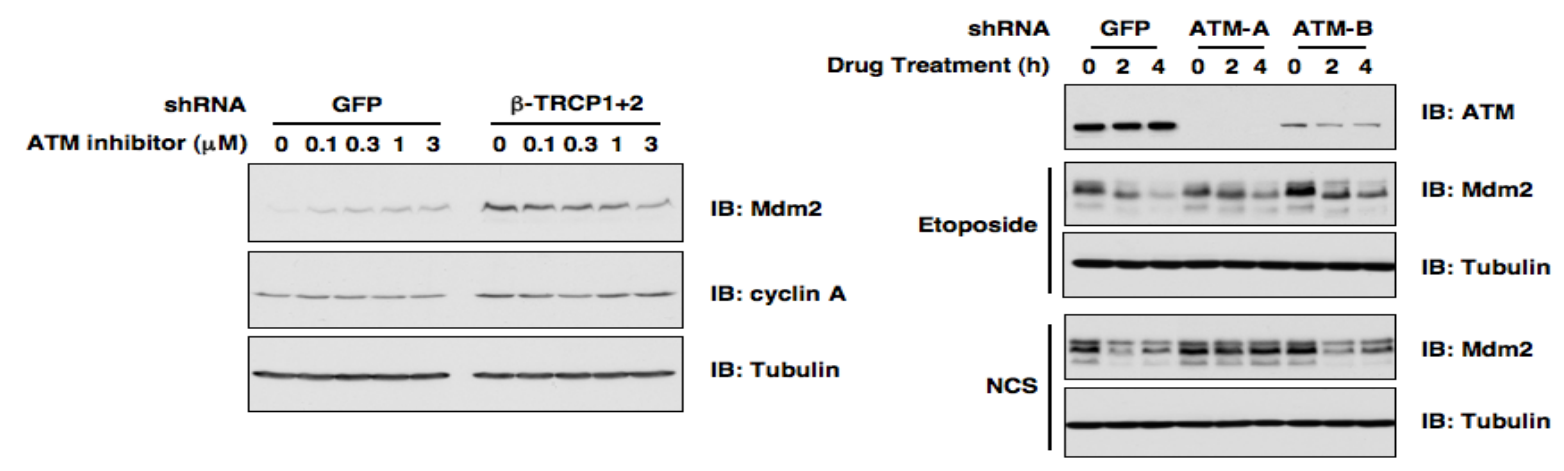

Figure 1: ATM is involved in DNA damage-induced Mdm2 destruction. (A) Immunoblot analysis of HeLa cells transfected with the indicated shRNA constructs. Cells were treated with the indicated concentrations of the ATM inhibitor for 12 hours before harvesting. (B) Endogenous ATM expression was depleted in U2OS cells by infecting with the indicated lentiviral shRNA constructs (with shGFP as a negative control) and selected with $1 \mu \mathrm{g} / \mathrm{ml}$ puromycin to eliminate the non-infected cells. The resulting U2OS cell lines were treated with etoposide or neocarzinostatin (NCS) for the indicated durations to induce Mdm2 destruction before harvesting for immunoblot analysis. the ATM (ataxia telangiectasia mutated) tumor suppressor protein can regulate $\mathrm{Mdm} 2$ under genotoxic stresses [1921]. ATM is one of the founding members of the PIKK (phosphatidyl inositol 3-kinase related kinase) family of kinases [22]. In response to DNA damage caused by UV exposure or reactive oxygen species (ROS), ATM is activated, which subsequently leads to the phosphorylation of p53. ATM-mediated phosphorylation of p53 disrupts the binding between Mdm2 and p53, resulting in enhanced p53 stability by escaping Mdm2-mediated ubiquitination [20]. In addition to $\mathrm{p} 53, \mathrm{Mdm} 2$ was also reported to undergo ATM-dependent phosphorylation on the Serine 395 (Ser395) residue in response to DNA damage [23]. Importantly, transgenic mice studies revealed that ATM phosphorylation of Mdm2 at Ser394 (equivalent to human Ser395 site) is required for $\mathrm{p} 53$ stabilization and activation after DNA damage [24]. These studies prompted us to further study whether the ATM kinase plays a critical role in $\mathrm{SCF}^{\text {-TRCP}}$-mediated $\mathrm{Mdm} 2$ proteolysis following DNA damaging signals.

In the present study, for the first time, we report that ATM indeed participates in $\beta$-TRCP-mediated Mdm2 ubiquitination and destruction. Moreover, our results demonstrate that phosphorylation of Mdm2 by ATM at Ser395 is not necessary for $\beta$-TRCP-mediated Mdm2 ubiquitination after DNA damage. On the other hand, ATM-dependent phosphorylation of CKI $\delta$ promotes CKI $\delta$ nuclear localization to trigger CKI $\delta$-mediated Mdm2 phosphorylation and subsequent destruction. Hence, our current study supports the critical role of ATM in $\mathrm{SCF}^{\beta-}$ ${ }^{\text {TRCP}}$-mediated Mdm2 degradation. Furthermore, our results suggest that ATM agonists could be used as anticancer agents, in part by accelerating $\mathrm{Mdm} 2$ destruction. 


\section{RESULTS}

\section{Mdm2 E3-ligase activity is not required for DNA damage-induced Mdm2 destruction}
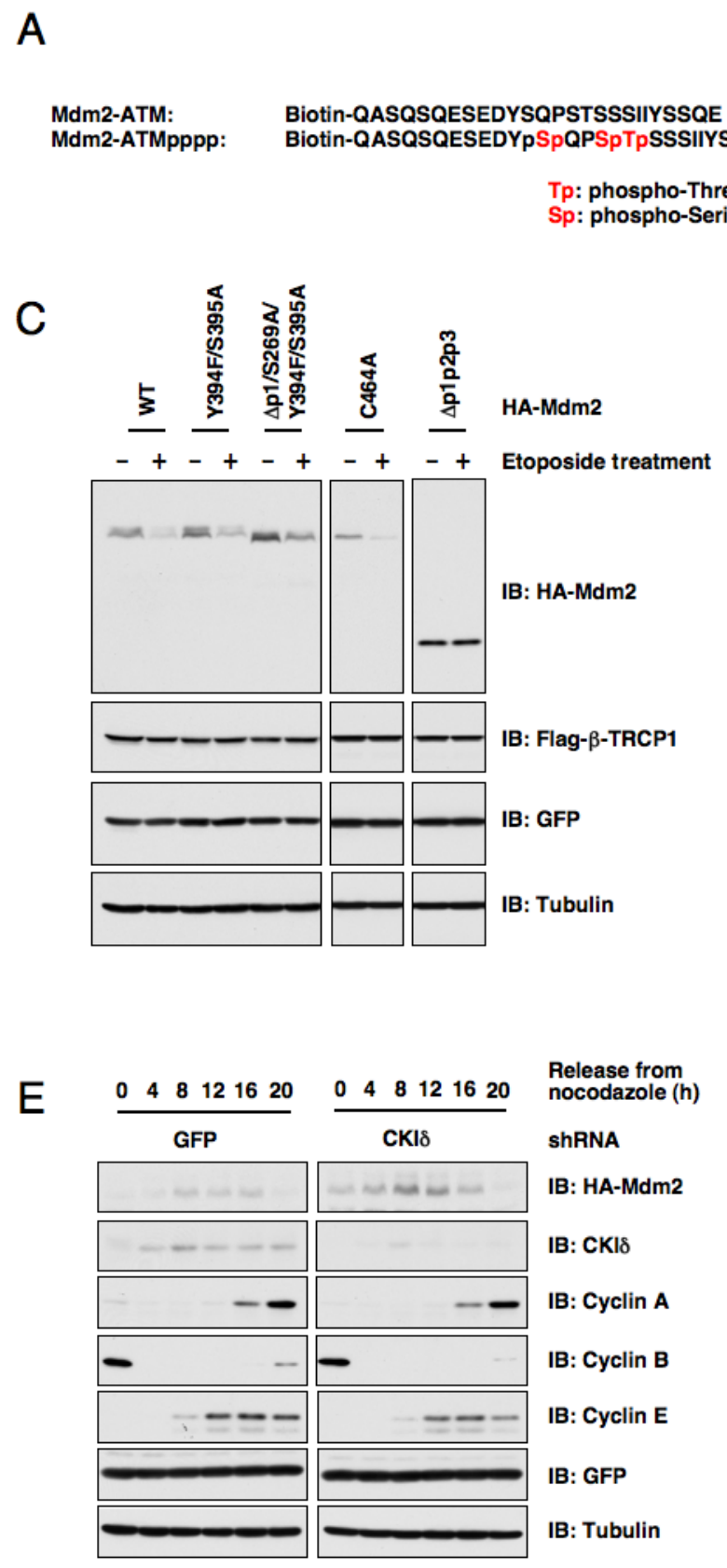

Consistent with previous reports [18], we found that in multiple cell lines, the $\mathrm{Mdm} 2$ oncoprotein became more unstable following DNA damaging agent, such as etoposide treatment (Supplemental Figures 1A-B). Studies from multiple laboratories have indicated that DNA-

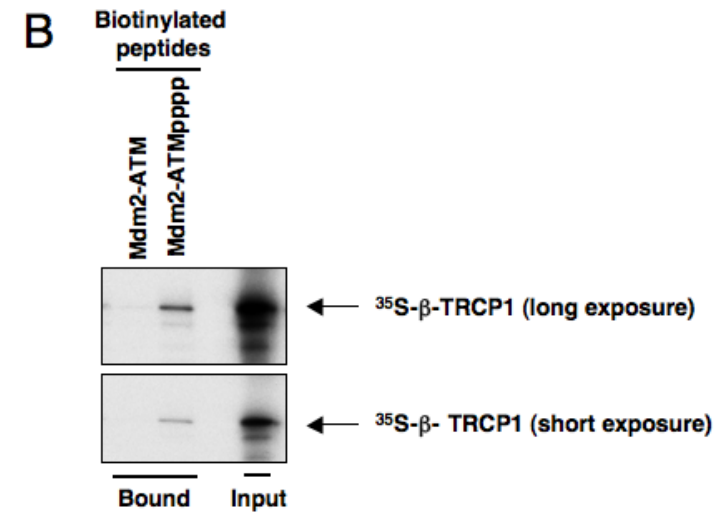

D
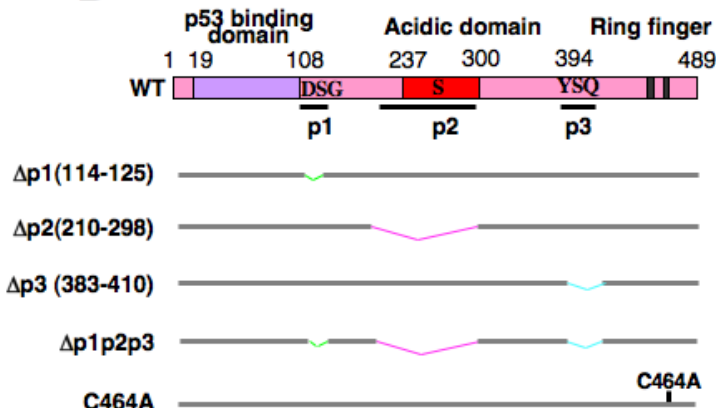

Figure 2: ATM-mediated phosphorylation of Mdm2 is not critical for Mdm2 destruction. (A) Schematic illustration of the biotinylated Mdm2 peptides used in this study. (B) Autoradiography of ${ }^{35}$ S-labeled $\beta$-TRCP1 bound to the indicated biotinylated peptides. (C) Casein Kinase I $\delta$ phosphorylates Mdm2 at multiple sites to trigger Mdm2 destruction mediated by $\beta$-TRCP1. Immunoblot analysis of U2OS cells transfected with the indicated HA-Mdm2 and Flag- $\beta-T R C P 1$ plasmids. A plasmid encoding GFP was used as a negative control for transfection efficiency. Thirty hours post-transfection, $25 \mu \mathrm{M}$ etoposide was used for up to three hours to trigger Mdm2 destruction before harvesting cells for immunoblots. (D) Schematic illustration of the various Mdm2 deletion mutants. p1, p2 and p3 are three identified PEST-sequence containing motifs that contain the identified CKI-phosphorylation sites. Loss of p1, p2, p3 creates a non-degradable mutant of $\mathrm{Mdm} 2(\Delta \mathrm{p} 1 \mathrm{p} 2 \mathrm{p} 3)$. C464A mutant form of Mdm2 lacks the E3 ubiquitin ligase activity, thus is defective in undergoing self-ubiquitination. (E) Immunoblot analysis of 293T cells transfected with HA-Mdm2 and the indicated shRNA constructs, after synchronization with nocodazole and release. 
damage could possibly augment Mdm2 auto-degradation $[25,26]$. However, a recent study demonstrated that the E3-ligase activity of Mdm2 might not be required for its destruction [27]. To solve this potential discrepancy, we continued to explore whether a Ring-finger mutant $\mathrm{Mdm} 2^{\mathrm{C} 464 \mathrm{~A}}$ that is defective in its E3 ubiquitin ligase activity, also became unstable upon DNA damaging treatments. In line with previous reports [18, 27], we found that $\mathrm{Mdm} 2^{\mathrm{C} 464 \mathrm{~A}}$ becomes unstable after treatment with a variety of DNA damaging agents including 5-FU, Doxorubicin, Actinomycin D (Supplemental Figures $1 \mathrm{C}-\mathrm{E})$. These results suggest that E3 ligase(s) other than Mdm2 itself, such as recently identified $\beta$-TRCP [18], might govern Mdm2 destruction under DNA damage
A

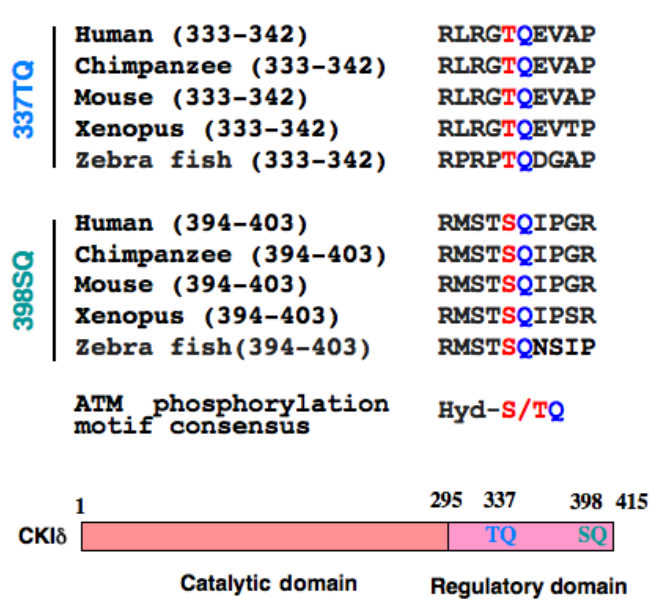

B

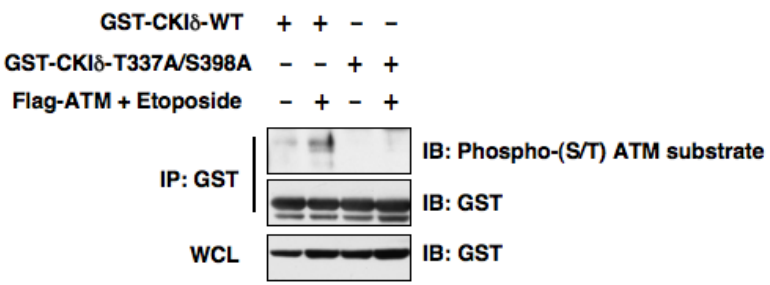

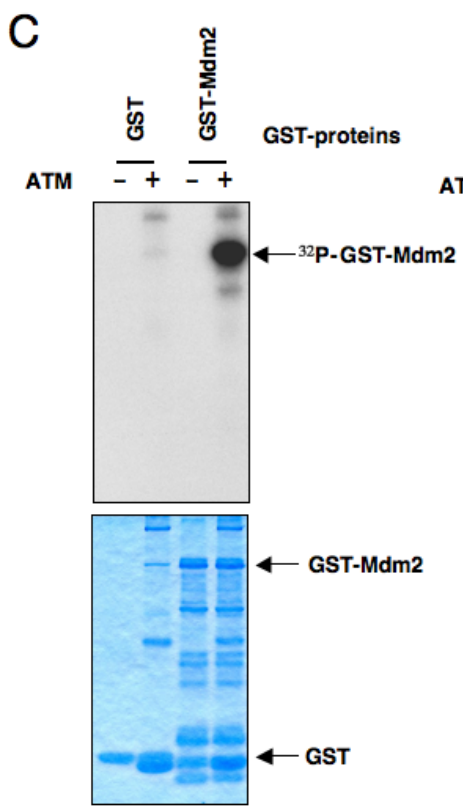

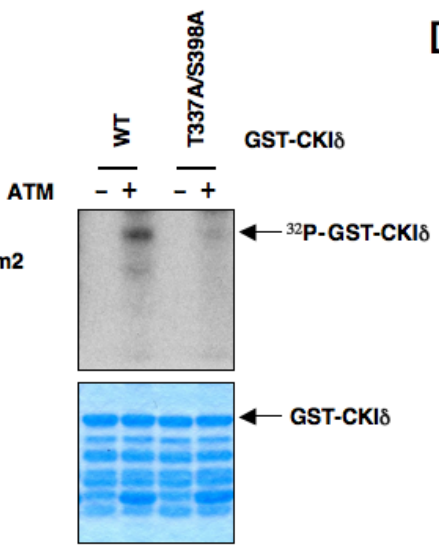

D

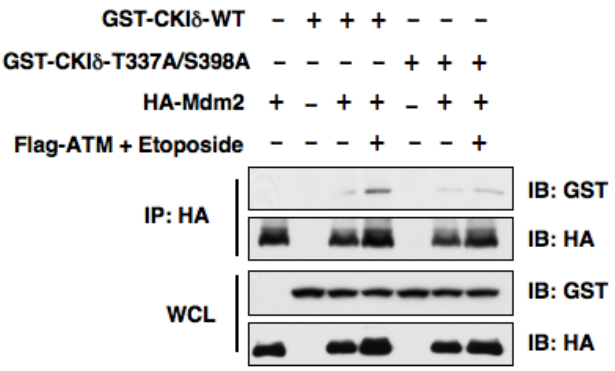

Figure 3: ATM phosphorylates Casein Kinase I $\delta$ to regulate its subcellular localization and its ability to interact with Mdm2. (A) Protein sequence illustration of the two putative ATM phosphorylation sites present in the C-terminus of CKI $\delta$ across different species. Hyd: hydrophobic amino acids. (B) Immunoblot analysis (IB) of whole cell lysates (WCL) and immunoprecipitates (IP) derived from 293T cells transfected with the indicated GST-CKI $\delta$ constructs in the presence or absence of Flag-ATM. Where indicated, the ATM kinase was activated by treatment with etoposide for 30 minutes before harvesting. The phosphorylation status of CKI $\delta$ by ATM in vivo was detected with a specific phospho-(S/T) ATM substrate antibody. (C) ATM phosphorylates both Mdm2 and CKI $\delta$ in vitro. The ATM kinase was purified by Flag-immunoprecipitation from 293T cells, and then incubated with $5 \mu \mathrm{g}$ of GST-Mdm2 or the indicated GST-CKI $\delta$ proteins (with GST protein as a negative control) in the presence of $\gamma^{-32}$-ATP. The kinase reaction products were resolved by SDS-PAGE and phosphorylation was detected by autoradiography. (D) Immunoblot (IB) analysis of whole cell lysates (WCL) and immunoprecipitates (IP) derived from 293T cells transfected with HA-Mdm2 and the indicated GST-CKI $\delta$ constructs. Thirty hours posttransfection, cells were pretreated with $10 \mu \mathrm{M}$ MG132 for 2 hours to block the proteasome pathway and then treated with $25 \mu \mathrm{M}$ etoposide (or DMSO as control) for 1.5 hours before harvesting. 
conditions. However, mechanistically, it remains largely unknown how DNA damaging signals are transduced to possibly control $\beta$-TRCP-mediated ubiquitination of $\mathrm{Mdm} 2$. As most $\beta$-TRCP substrates require priorphosphorylation for recognition by $\beta$-TRCP [28], it is critical to reveal the upstream signaling pathway(s) that are activated by DNA damage to trigger $\beta$-TRCP-mediated timely destruction of Mdm2.

\section{ATM is involved in DNA damage-induced Mdm2 destruction}

Given the pivotal role of ATM in DNA damage response, we started our investigation by examining whether ATM participates in Mdm2 stability control. In keeping with our previous report [18], depletion of both isoforms of endogenous $\beta$-TRCP ( $\beta$-TRCP1 and $\beta$-TRCP2) led to a significant increase of Mdm2 protein

A

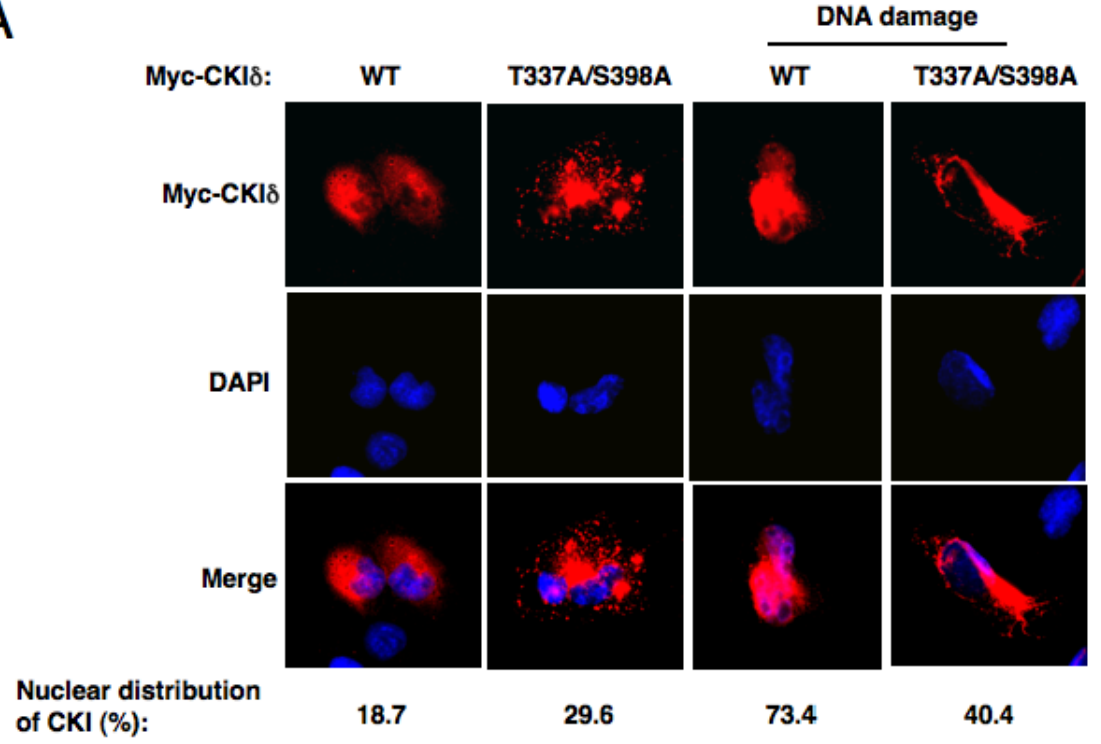

B

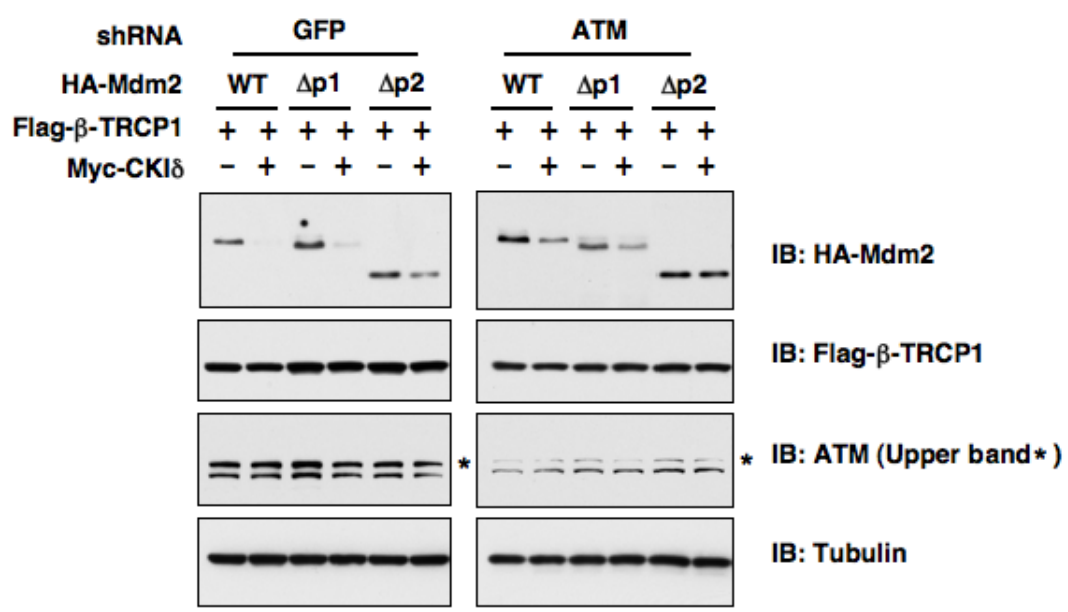

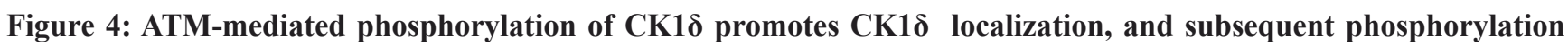
of Mdm2 to trigger Mdm2 degradation. (A) ATM-mediated phosphorylation of CK1 $\delta$ promotes CK1 $\delta$ nuclear localization. Immunofluorescence and DAPI staining of U2OS cells transfected with the indicated Myc-CKI $\delta$ constructs. Cells were treated with or without $10 \mu \mathrm{M}$ doxorubicin for 1 hour before fixation. (B) Stability of the Mdm2 protein is controlled by ATM. U2OS cells were infected with the indicated lentiviral shRNA construct and selected with $1 \mu \mathrm{g} / \mathrm{ml}$ puromycin to eliminate the non-infected cells. The resulting U2OS cell lines were transfected with the indicated HA-Mdm2, Flag- $\beta$-TRCP1 and Myc-CKI $\delta$ constructs. Immunoblots were performed to monitor the changes of HA-Mdm2. p1 and p2 are two of the three identified major PEST-sequence containing motifs that contain the identified CKI-phosphorylation sites. 
abundance (Figure 1A). More interestingly, inactivation of ATM kinase by its pharmaceutical inhibitor [16, 29], led to a dose-dependent increase in Mdm2 abundance as well in shGFP-treated control HeLa cells (Figure 1A). However, ATM inhibitor could not induce Mdm2 expression in sh $\beta$-TRCP-treated HeLa cells, indicating that ATM might govern Mdm2 stability in a $\beta$-TRCP-dependent manner. Notably, consistent with previous reports [30-32], depletion of endogenous ATM with multiple independent shRNA vectors moderately affected Mdm2 destruction in response to various DNA damaging agents (Figure 1B). These results indicate a possible role for the ATM signaling pathway in regulating DNA damage-induced Mdm2 destruction. The next critical question we intended to address is to determine which is the major downstream signaling route through which DNA damage-induced activation of ATM influences Mdm2 stability.

\section{ATM-mediated phosphorylation of Mdm2 is not critical for Mdm2 destruction}

As Mdm2 has been reported to be phosphorylated by ATM at the Ser395 site, we continued our study by examining whether direct phosphorylation of $\mathrm{Mdm} 2$ by ATM affects Mdm2 interaction with its E3 ligase, $\beta$-TRCP1. Using immobilized biotinylated Mdm2 peptides derived from the range spanning the identified ATM phosphorylation site (Ser395) (Figure 2A), we found that a phosphorylation event occurring at Ser395 could trigger Mdm2 interaction with $\beta$-TRCP1 (Figure 2B). It is thus possible that ATM-phosphorylation on Ser395 in Mdm2 may prime for the subsequent CKI-mediated phosphorylation. However, we found that mutation of the Ser395 site did not affect etoposide-induced Mdm2 destruction (Figures 2C-D). Furthermore, overexpression of ATM alone failed to significantly trigger $\mathrm{Mdm} 2$ destruction, or to promote $\mathrm{Mdm} 2$ ubiquitination in vitro (data not shown), indicating that ATM may require other kinase(s) to synergistically regulate $\mathrm{Mdm} 2$ degradation. Since our previous studies identified CKI $\delta$ as an upstream kinase responsible for Mdm2 destruction (Figure 2E) [18], it was thus of great interest for us to further investigate whether ATM promotes Mdm2 degradation mainly by influencing $\mathrm{CKI} \delta$-mediated phosphorylation of Mdm2.

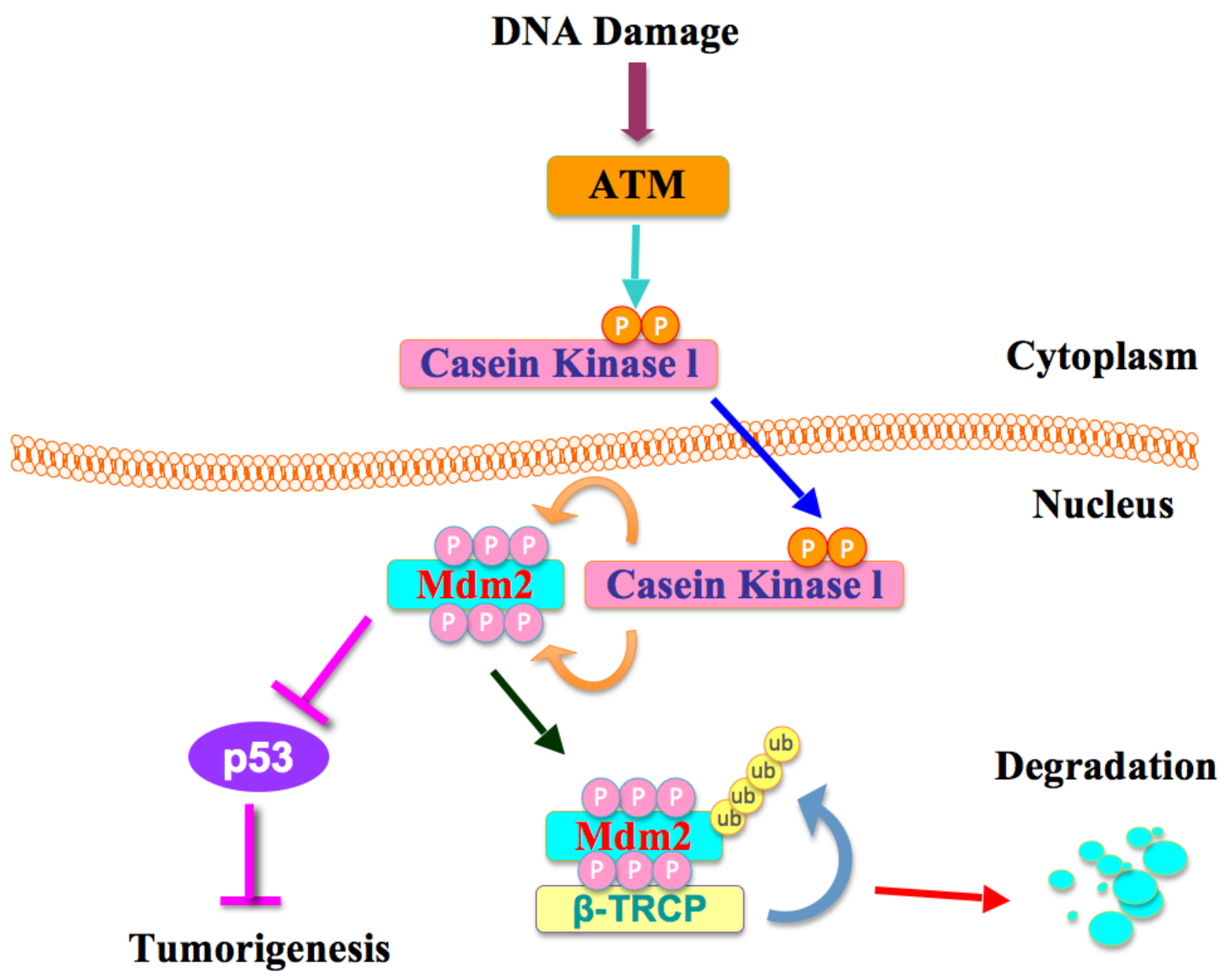

Figure 5: A proposed role for the ATM in $\beta$-TRCP-mediated Mdm2 ubiquitination and destruction. 


\section{ATM phosphorylates CKI $\delta$ to possibly regulate its ability to interact with, and subsequently promote Mdm2 destruction}

Although CKI has been reported to be activated by DNA damage in Drosophila cells [33], the exact molecular mechanisms of how CKI is activated following DNA damaging treatment in human cells are largely unknown. Upon subsequent examination of the CKI $\delta$ protein sequence, we found two well-conserved potential ATM phosphorylation [34] sites in its regulatory domain (Figure 3A). In keeping with this finding, we found that ATM could phosphorylate $\mathrm{CKI} \delta$ (Figures 3B-C) to potentially regulate its ability to interact with Mdm2 (Figure 3D). As a result, etoposide treatment, which activates ATM kinase, promotes CKI $\delta$ and Mdm2 interaction while the CKI $\delta$ mutant (CKI $\delta$-T337A/S398A), where the two conserved ATM sites were inactivated, failed to interact with Mdm2 upon etoposide treatment (Figure 3D).

\section{ATM-mediated phosphorylation of CK1 $\delta$

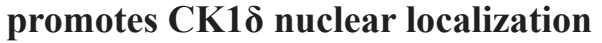

To further understand the molecular mechanisms underlying how DNA damaging signals may potentially regulate CKI $\delta$ activity, we immunoprecipitated CKI $\delta$ from U2OS cells after treatment with etoposide for the indicated time periods to measure its kinase activity. The CKI $\delta$ activity changes were indicated by its ability to phosphorylate recombinant Skp2 or CKI $\delta$ itself in vitro. Surprisingly, we only detected a moderate increase in the intrinsic CKI $\delta$ kinase activity in response to DNA damage (Supplemental Figures S2A-B). These results indicate that rather than directly regulating the CKI $\delta$ kinase activity, DNA damaging signals might influence the association of CKI $\delta$ with its substrates including $\mathrm{Mdm} 2$ by controlling CKI $\delta$ cellular localization. In support of this notion, we found that in agreement with a previous report [35], CKI $\delta$ mainly resides in the cytoplasm in non-stressed cells. However, in response to DNA damage, a significant fraction of endogenous CKI $\delta$ translocated into the nucleus to interact with, and modify, the Mdm2 protein (Figure 4A). More importantly, we showed that inactivation of the two putative ATM sites, which are located at the C-terminus of CKI $\delta$, disrupts its ability to enter the nucleus following DNA damage (Figure 4A). This result strongly suggests that ATM plays an important role in DNA damage-induced nuclear translocation of CKI $\delta$ to promote $\mathrm{CKI} \delta$-mediated $\mathrm{Mdm} 2$ phosphorylation, which might influence the subsequent $\mathrm{Mdm} 2$ ubiquitination and destruction mediated by the $\beta-\mathrm{TRCP} / \mathrm{CKI} \delta$ signaling axis. Furthermore, in support of a critical role of ATM in $\beta$-TRCP/CKI $\delta$-mediated $\mathrm{Mdm} 2$ destruction, we found that depletion of endogenous ATM attenuated the destruction of ectopically expressed WT-Mdm2, $\Delta \mathrm{p} 1$ -
$\mathrm{Mdm} 2$ or $\Delta \mathrm{p} 2-\mathrm{Mdm} 2$ after co-expression of both $\beta$-TRCP and $\mathrm{CKI} \delta$ (Figure 4B). On the other hand, consistent with our previous report [18], depleting all possible $\beta$-TRCPrecognizable degrons containing the identified CKI $\delta$ phosphorylation sites created a non-degradable Mdm2 $(\Delta \mathrm{p} 1 \mathrm{p} 2 \mathrm{p} 3-\mathrm{Mdm} 2)$ that resists the destruction effects mediated by co-expressing $\beta$-TRCP and CKI $\delta$ (data not shown). These results elucidated the specificity of this in vivo degradation assay, and further implicated that CKI $\delta$ dependent phosphorylation events is the major signaling route through which DNA damage-dependent activation of ATM might control timely turnover of Mdm2 during genotoxic stress.

\section{DISCUSSION}

Cells have complex mechanisms to protect their genomes from various endogenous and exogenous stressors including UV exposure, $\gamma$-irradiation, ROS, and mutagens, which cause DNA damage [36]. For example, cells have multiple repair mechanisms and checkpoint responses to maintain their genomic stability. DNA damage responses are governed by multiple signaling pathways including the ATM-Chk2 and ATR-Chk1 pathways [37]. It has been reported that DNA damage leads to ATM-dependent USP7S (a specific isoform of USP7) dephosphorylation by PPM1G (protein phosphatase magnesium-dependent 1 gamma), thus resulting in the inactivation and degradation of USP7S to promote Mdm2 ubiquitination and degradation [38]. Although activation of ATM has been found to be crucial for DNA damage responses, the underlying molecular mechanisms are largely unknown. Here we report that DNA damage activates ATM, which subsequently phosphorylates CKI $\delta$ to promote its translocation into the nucleus where phosphorylation of $\mathrm{Mdm} 2$ by $\mathrm{CKI} \delta$ ultimately triggers Mdm2 degradation by SCF ${ }^{\beta-T R C P}$ (Figure 5).

It has been shown that the inhibitory function of Mdm2 towards p53 plays a major role in modulating p53 activity following DNA damage, a process that is subjected to many layers of regulation [39]. Among them, the ATM/ATR/Chk kinase cascade induced by DNA damage has an important function in the regulation of p53 activity in part by directly phosphpryating p53 [40]. Inhibition of ATM resulted in p53 shift from the nuclear to cytosolic fractions, which inactivates its transcriptional activity [41]. Furthermore, ATM has been demonstrated to phosphorylate Mdm2 at Ser395 [23]. Mechanistically, ATM phosphorylation of Mdm2 inhibits the ability of $\mathrm{Mdm} 2$ to poly-ubiquitinate $\mathrm{p} 53$, thereby resulting in $\mathrm{p} 53$ stabilization [42]. This prompted us to explore whether ATM participates in Mdm2 stability control. Indeed, we found that the use of an ATM inhibitor increased Mdm2 abundance in control HeLa cells, but not in $\beta$-TRCPdepleted HeLa cells, suggesting that ATM could govern Mdm2 stability in a $\beta$-TRCP-dependent manner. However, 
inactivating Ser395 in Mdm2 did not significantly stabilize Mdm2 under DNA damaging conditions, arguing that ATM may control Mdm2 turnover by phosphorylating other critical components of the $\mathrm{Mdm} 2$ destruction pathway. In support of this notion, we found that in response to DNA damage, activation of the ATM kinase directly phosphorylates CKI $\delta$ at its C-terminus to regulate its subcellular localization and interaction with $\mathrm{Mdm} 2$ (Figure 3A). These data indicate that DNA damage primarily modulates the accessibility of $\mathrm{CKI} \delta$ cellular localization (Figure 4A) rather than its kinase activity (Supplemental Figures S2A-B) to influence Mdm2 stability.

On the basis of our results, we propose a hypothetical model by which ATM is the upstream kinase that following activation by DNA damaging signals, could phosphorylate CKI $\delta$ to potentially regulate its subcellular localization and its ability to interact with and regulate Mdm2 (Figure 5). However, we recognize that ATM may also phosphorylate other unknown substrates to affect Mdm2 turnover. Therefore, further in-depth studies are needed to investigate the precise molecular mechanism of how ATM affects CKI $\delta$ cellular localization, as well as how ATM and CKI $\delta$ work synergistically to promote Mdm2 destruction following DNA damage. In summary, we presented experimental evidence that strongly supports the pivotal roles of ATM in $\beta$-TRCP-mediated Mdm2 degradation. Since ATM and CK1 synergistically control $\beta$-TRCP-mediated Mdm2 ubiquitination and destruction, our work provides a rational for the use of CKI and/or ATM agonists as anti-cancer agents to promote Mdm2 destruction, which might improve the overall survival of patients diagnosed with cancer in the future.

\section{MATERIALS AND METHODS}

\section{Plasmids}

HA-Mdm2 construct was kind gift from Dr. Jiandong Chen. Various Mdm2 and CKI $\delta$ mutants were generated using the QuikChange XL Site-Directed Mutagenesis Kit (Stratagene) according to the manufacturer's instructions. The C-terminus fragment (aa 285-415) of CKI $\delta$ was subcloned using the Pfu polymerase (Stratagene) into the pGEX vector to create GST-CKI $\delta$ in frame fusion proteins. Flag- $\beta$-TRCP1, shRNA- $\beta$-TRCP1+2, shTRCP1, shTRCP2, and shRNA-GFP constructs were described previously [43, 44]. Flag-ATM construct was obtained from Michael Kastan. shRNA constructs against various CKI isoforms were obtained from Dr. Jianping Jin. Lentiviral shRNA constructs against GFP, ATM and CKI $\delta$ were obtained from Dr. William Hahn.

\section{Antibodies and Reagents}

Anti-cyclin A (SC-751), anti-cyclin B (SC-245), anti-cyclin E (SC-247), anti-Casein Kinase I $\delta$ (R-19) (SC-6474) and polyclonal anti-HA (SC-805) antibodies were purchased from Santa Cruz. Polyclonal anti-FLAG (F2425), monoclonal anti-FLAG (F-3165), peroxidaseconjugated anti-mouse secondary antibody (A4416), peroxidase-conjugated anti-rabbit secondary antibody (A4914), and Anti-tubulin (T-5168) antibodies were purchased from Sigma. Monoclonal anti-HA antibody (MMS-101P) was purchased from Covance. The antiGFP (632380) antibody was purchased from Invitrogen. The anti-phospho-Ser1981 ATM (4526) antibody was purchased from Cell Signaling. Anti-Mdm2 (Ab1:OP46) was purchased from Calbiochem. Oligofectamine, Lipofectamine and Plus reagents were purchased from Invitrogen.

\section{Immunoblots and Immunoprecipitation}

Cells were lysed in EBC (50 mM Tris $\mathrm{pH} 8.0$, $120 \mathrm{mM} \mathrm{NaCl}, 0.5 \%$ NP-40) buffer supplemented with protease inhibitors (Complete Mini, Roche) and phosphatase inhibitors (phosphatase inhibitor cocktail set I and II, Calbiochem). The protein concentrations of the lysates were measured using the Bio-Rad protein assay reagent on a Beckman Coulter DU-800 spectrophotometer. The lysates were then resolved by SDS-PAGE and immunoblotted with indicated antibodies. For immunoprecipitation, $800 \mu \mathrm{g}$ lysates were incubated with the appropriate antibody (1-2 g) for 3-4 hours at $4 \mathrm{C}$ followed by one hour-incubation with Protein A sepharose beads (GE Healthcare). Immuno-complexes were washed five times with NETN buffer (20 mM Tris, $\mathrm{pH} 8.0,100$ $\mathrm{mM} \mathrm{NaCl}, 1 \mathrm{mM}$ EDTA and 0.5\% NP-40) before being resolved by SDS-PAGE and immunoblotted with indicated antibodies.

\section{In vitro Kinase Assay}

293T cells were transfected with FlagATM constructs. Forty-eight hours later, ATM was immunoprecipitated using Flag-matrix (Sigma). Afterwards, it was incubated with $5 \mu \mathrm{g}$ of indicated GST fusion proteins in the presence of $5 \mu \mathrm{Ci}\left[\gamma_{-}{ }^{32} \mathrm{P}\right]$ ATP and $20 \mu \mathrm{M}$ cold ATP in the ATM kinase reaction buffer for 15-30 minutes. The reaction was stopped by the addition of SDS-containing lysis buffer, resolved on SDS-PAGE, and detected by autoradiography. Casein Kinase $I \delta$ was purchased from New England Biolabs. The Casein Kinase I in vitro kinase assay was performed according to the manufacturer's instructions (New England Biolabs). Briefly, $5 \mu \mathrm{g}$ of indicated GST fusion proteins were 
incubated with purified active Casein Kinase I in the presence of $5 \mu \mathrm{Ci}\left[\gamma_{-}{ }^{32} \mathrm{P}\right]$ ATP and $200 \mu \mathrm{M}$ cold ATP in the Casein Kinase I reaction buffer for 15-30 minutes. The reaction was stopped by the addition of SDS-containing lysis buffer, resolved on SDS-PAGE, and detected by autoradiography.

\section{Immunofluorescence Microscopy}

Cells were fixed with $4 \%$ paraformaldehyde for 10 min, permeabilized in $0.5 \%$ Triton $\mathrm{X}-100$ for $10 \mathrm{~min}$, and incubated in PBS and 10\% goat serum blocking solution for $1 \mathrm{~h}$. The cells were incubated for $2 \mathrm{~h}$ with anti-CK $1 \delta$ in $5 \%$ goat serum and were stained for $1 \mathrm{~h}$ with Alexa Fluor 594-conjugated secondary antibody (1:500). The slides were mounted with mounting medium containing antifade reagent and 4,6-diamidino-2-phenylindole. Cells were viewed under fluorescence microscope.

\section{ACKNOWLEDGEMENTS}

This work was supported by grants from the National Institute of General Medicine, NIH (GM089763, GM094777) to W.W. W.W is an American Cancer Society Scholar. Z. W is supported by NIH NRSA fellowship. H.I is supported by NIH K01 (AG041218).

\section{Conflict of Interest}

The authors declare that they have no conflict of interest.

\section{REFERENCE}

1. Siegel R, Naishadham D and Jemal A. Cancer statistics, 2012. CA Cancer J Clin. 2012; 62(1):10-29.

2. Freed-Pastor WA and Prives C. Mutant p53: one name, many proteins. Genes Dev. 2012; 26(12):1268-1286.

3. Menendez D, Inga A and Resnick MA. The expanding universe of p53 targets. Nat Rev Cancer. 2009; 9(10):724737.

4. Meek DW. Tumour suppression by p53: a role for the DNA damage response? Nat Rev Cancer. 2009; 9(10):714-723.

5. Toledo F and Wahl GM. Regulating the p53 pathway: in vitro hypotheses, in vivo veritas. Nat Rev Cancer. 2006; 6(12):909-923.

6. Oliner JD, Pietenpol JA, Thiagalingam S, Gyuris J, Kinzler KW and Vogelstein B. Oncoprotein MDM2 conceals the activation domain of tumour suppressor p53. Nature. 1993; 362(6423):857-860.

7. Rolfe M, Beer-Romero P, Glass S, Eckstein J, Berdo I, Theodoras A, Pagano M and Draetta G. Reconstitution of p53-ubiquitinylation reactions from purified components: the role of human ubiquitin-conjugating enzyme UBC4 and
E6-associated protein (E6AP). Proc Natl Acad Sci U S A. 1995; 92(8):3264-3268.

8. Yang X, Li H, Zhou Z, Wang WH, Deng A, Andrisani $\mathrm{O}$ and Liu X. Plk1-mediated phosphorylation of Topors regulates p53 stability. J Biol Chem. 2009; 284(28):1858818592.

9. Coumailleau F, Das V, Alcover A, Raposo G, VandormaelPournin S, Le Bras S, Baldacci P, Dautry-Varsat A, Babinet $\mathrm{C}$ and Cohen-Tannoudji M. Over-expression of Rififylin, a new RING finger and FYVE-like domain-containing protein, inhibits recycling from the endocytic recycling compartment. Mol Biol Cell. 2004; 15(10):4444-4456.

10. Dornan D, Wertz I, Shimizu H, Arnott D, Frantz GD, Dowd P, O'Rourke K, Koeppen H and Dixit VM. The ubiquitin ligase COP1 is a critical negative regulator of p53. Nature. 2004; 429(6987):86-92.

11. Jung YS, Qian Y and Chen X. Pirh2 RING-finger E3 ubiquitin ligase: its role in tumorigenesis and cancer therapy. FEBS Lett. 2012; 586(10):1397-1402.

12. Montes de Oca Luna R, Wagner DS and Lozano G. Rescue of early embryonic lethality in mdm2-deficient mice by deletion of p53. Nature. 1995; 378(6553):203-206.

13. Jones SN, Roe AE, Donehower LA and Bradley A. Rescue of embryonic lethality in Mdm2-deficient mice by absence of p53. Nature. 1995; 378(6553):206-208.

14. Manfredi JJ. The Mdm2-p53 relationship evolves: Mdm2 swings both ways as an oncogene and a tumor suppressor. Genes Dev. 2010; 24(15):1580-1589.

15. Miliani de Marval PL and Zhang Y. The RP-Mdm2-p53 pathway and tumorigenesis. Oncotarget. 2011; 2(3):234238.

16. Azmi AS, Banerjee S, Ali S, Wang Z, Bao B, Beck FW, Maitah M, Choi M, Shields TF, Philip PA, Sarkar FH and Mohammad RM. Network modeling of MDM2 inhibitoroxaliplatin combination reveals biological synergy in wtp53 solid tumors. Oncotarget. 2011; 2(5):378-392.

17. Inuzuka H, Fukushima H, Shaik S and Wei W. Novel insights into the molecular mechanisms governing Mdm2 ubiquitination and destruction. Oncotarget. 2010; 1(7):685690.

18. Inuzuka $\mathrm{H}$, Tseng $\mathrm{A}$, Gao $\mathrm{D}$, Zhai $\mathrm{B}$, Zhang Q, Shaik S, Wan L, Ang XL, Mock C, Yin H, Stommel JM, Gygi S, Lahav G, Asara J, Xiao ZX, Kaelin WG, Jr., et al. Phosphorylation by casein kinase I promotes the turnover of the Mdm2 oncoprotein via the SCF(beta-TRCP) ubiquitin ligase. Cancer Cell. 2010; 18(2):147-159.

19. Taira N, Yamamoto H, Yamaguchi T, Miki Y and Yoshida K. ATM augments nuclear stabilization of DYRK2 by inhibiting MDM2 in the apoptotic response to DNA damage. J Biol Chem. 2010; 285(7):4909-4919.

20. Cheng Q, Chen L, Li Z, Lane WS and Chen J. ATM activates $\mathrm{p} 53$ by regulating MDM2 oligomerization and E3 processivity. EMBO J. 2009; 28(24):3857-3867.

21. Chang L, Zhou B, Hu S, Guo R, Liu X, Jones SN and Yen 
Y. ATM-mediated serine 72 phosphorylation stabilizes ribonucleotide reductase small subunit p53R2 protein against MDM2 to DNA damage. Proc Natl Acad Sci U S A. 2008; 105(47):18519-18524.

22. Derheimer FA and Kastan MB. Multiple roles of ATM in monitoring and maintaining DNA integrity. FEBS Lett. 2010; 584(17):3675-3681.

23. Maya R, Balass M, Kim ST, Shkedy D, Leal JF, Shifman O, Moas M, Buschmann T, Ronai Z, Shiloh Y, Kastan MB, Katzir E and Oren M. ATM-dependent phosphorylation of $\mathrm{Mdm} 2$ on serine 395: role in p53 activation by DNA damage. Genes Dev. 2001; 15(9):1067-1077.

24. Gannon HS, Woda BA and Jones SN. ATM phosphorylation of Mdm2 Ser394 regulates the amplitude and duration of the DNA damage response in mice. Cancer Cell. 2012; 21(5):668-679.

25. Fang S, Jensen JP, Ludwig RL, Vousden KH and Weissman AM. Mdm2 is a RING finger-dependent ubiquitin protein ligase for itself and p53. J Biol Chem. 2000; 275(12):89458951.

26. Stommel JM and Wahl GM. Accelerated MDM2 autodegradation induced by DNA-damage kinases is required for p53 activation. EMBO J. 2004; 23(7):1547-1556.

27. Itahana $\mathrm{K}, \mathrm{Mao} \mathrm{H}$, Jin A, Itahana $\mathrm{Y}$, Clegg HV, Lindstrom MS, Bhat KP, Godfrey VL, Evan GI and Zhang Y. Targeted inactivation of Mdm2 RING finger E3 ubiquitin ligase activity in the mouse reveals mechanistic insights into p53 regulation. Cancer Cell. 2007; 12(4):355-366.

28. Frescas D and Pagano M. Deregulated proteolysis by the F-box proteins SKP2 and beta-TrCP: tipping the scales of cancer. Nat Rev Cancer. 2008; 8(6):438-449.

29. Pei D, Zhang $Y$ and Zheng J. Regulation of p53: a collaboration between Mdm2 and Mdmx. Oncotarget. 2012; 3(3):228-235.

30. Meulmeester E, Pereg Y, Shiloh Y and Jochemsen AG. ATM-mediated phosphorylations inhibit $\mathrm{Mdmx} / \mathrm{Mdm} 2$ stabilization by HAUSP in favor of p53 activation. Cell Cycle. 2005; 4(9):1166-1170.

31. Khosravi R, Maya R, Gottlieb T, Oren M, Shiloh Y and Shkedy D. Rapid ATM-dependent phosphorylation of MDM2 precedes p53 accumulation in response to DNA damage. Proc Natl Acad Sci U S A. 1999; 96(26):1497314977.

32. Lu X, Ma O, Nguyen TA, Jones SN, Oren M and Donehower LA. The Wip1 Phosphatase acts as a gatekeeper in the p53-Mdm2 autoregulatory loop. Cancer Cell. 2007; 12(4):342-354.

33. Santos JA, Logarinho E, Tapia C, Allende CC, Allende JE and Sunkel CE. The casein kinase 1 alpha gene of Drosophila melanogaster is developmentally regulated and the kinase activity of the protein induced by DNA damage. J Cell Sci. 1996; 109 ( Pt 7):1847-1856.

34. Jin VX, Rabinovich A, Squazzo SL, Green R and Farnham PJ. A computational genomics approach to identify cis- regulatory modules from chromatin immunoprecipitation microarray data--a case study using E2F1. Genome Res. 2006; 16(12):1585-1595.

35. Alsheich-Bartok O, Haupt S, Alkalay-Snir I, Saito S, Appella E and Haupt Y. PML enhances the regulation of p53 by CK1 in response to DNA damage. Oncogene. 2008; 27(26):3653-3661.

36. Fu D, Calvo JA and Samson LD. Balancing repair and tolerance of DNA damage caused by alkylating agents. Nat Rev Cancer. 2012; 12(2):104-120.

37. Smith J, Tho LM, Xu N and Gillespie DA. The ATM-Chk2 and ATR-Chk1 pathways in DNA damage signaling and cancer. Adv Cancer Res. 2010; 108:73-112.

38. Khoronenkova SV, Dianova, II, Ternette N, Kessler BM, Parsons JL and Dianov GL. ATM-dependent downregulation of USP7/HAUSP by PPM1G activates $\mathrm{p} 53$ response to DNA damage. Mol Cell. 2012; 45(6):801-813.

39. Wang $Z$ and Li B. Mdm 2 links genotoxic stress and metabolism to p53. Protein Cell. 2010; 1(12):1063-1072.

40. Reinhardt HC, Aslanian AS, Lees JA and Yaffe MB. p53deficient cells rely on ATM- and ATR-mediated checkpoint signaling through the p38MAPK/MK2 pathway for survival after DNA damage. Cancer Cell. 2007; 11(2):175-189.

41. Pang LY, Scott M, Hayward RL, Mohammed H, Whitelaw CB, Smith GC and Hupp TR. p21(WAF1) is component of a positive feedback loop that maintains the p53 transcriptional program. Cell Cycle. 2011; 10(6):932-950.

42. Cheng $Q$ and Chen J. Mechanism of $\mathrm{p} 53$ stabilization by ATM after DNA damage. Cell Cycle. 2010; 9(3):472-478.

43. Jin J, Shirogane T, Xu L, Nalepa G, Qin J, Elledge SJ and Harper JW. SCFbeta-TRCP links Chk1 signaling to degradation of the Cdc25A protein phosphatase. Genes Dev. 2003; 17(24):3062-3074.

44. Shirogane T, Jin J, Ang XL and Harper JW. SCFbeta-TRCP controls clock-dependent transcription via casein kinase 1-dependent degradation of the mammalian period-1 (Per1) protein. J Biol Chem. 2005; 280(29):26863-26872. 